\title{
What Determine the International Competitiveness of Chinese Publishing Industry?
}

\author{
Long Wei, Hui Yang \\ School of Economics, Wuhan University of Technology, Wuhan, China \\ Email: longwei@whut.edu.cn
}

How to cite this paper: Wei, L. and Yang, H. (2019) What Determine the International Competitiveness of Chinese Publishing Industry? American Journal of Industrial and Business Management, 9, 789-798. https://doi.org/10.4236/ajibm.2019.94052

Received: March 11, 2019

Accepted: April 1, 2019

Published: April 4, 2019

Copyright ( 2019 by author(s) and Scientific Research Publishing Inc. This work is licensed under the Creative Commons Attribution International License (CC BY 4.0).

http://creativecommons.org/licenses/by/4.0/ c) (i) Open Access

\begin{abstract}
Recent years have witnessed a higher involvement of China's publishing sector in international market. For the purpose of revealing the dominant factors influencing the international competitiveness of Chinese publishing industry, this paper conducts Gray Relational Analysis to identify certain factors that affect the international competitiveness of China's publishing industry based on the comparison series and the reference series. The results of empirical analysis indicate that human capital as an advanced factor plays a leading role in the international competitiveness of Chinese publishing industry. Industrial competition obviously affects the scale of China's publishing industry and its competitiveness. The demand for cultural consumption drives the upgrading of China's publishing industry, and enhances its international competitiveness. The government's support facilitates the enhancement of the international competitiveness of Chinese publishing industry. Finally, the author gives some policy suggestions from the perspective of cultural resources, broadening industry chain and governmental conducts.
\end{abstract}

\section{Keywords}

Publishing Industry, International Competitiveness, Gray Relational Analysis

\section{Introduction and Literature Review}

After China's accession to the WTO in 2002, its commitments to the opening up of intellectual property and service trade continued to be implemented. The publishing industry is a topic of great concern to the major members of the multilateral trade framework negotiations. Due to the particularity of the publishing products, China has proposed a number of restrictive clauses while committing to open the market for publishing products. The internationalization trend of China's publishing industry is becoming more obvious now, and the basic pat- 
tern of government-driven, enterprise-led and market-oriented operation has initially formed. The publishing industry in China is prosperous, and with the deep integration of publishing industry and the development of copyright trade, the international competitiveness of China's publishing industry has become an important issue.

The publishing industry is an important sector of the cultural industry. At present, the research on international competition in the publishing industry mainly focuses on the influencing factors and evaluation methods of its international competitiveness. In terms of influencing factors, Zhang and Du examined the cultural industry competitiveness of the United States from the indicators of Revealed Comparative Advantage Index (RCA), Net Export Revealed Comparative Advantage Index (NXRCA), International Market Share (MS) and Industrial Profit [1]. They believe that cultural industry development strategy, economic environment, government behavior, corporate mergers and acquisitions are the main factors affecting the development of cultural industries. Tang and Li analyzed the mechanism of the formation of the international competitiveness of Japanese cultural industry, and believed that the government's high support, the company's own strength, the talents, the development of derivative markets, the construction of amusement facilities and international cultural exchanges have all contributed to the development of Japanese cultural industry [2]. Lan and Han constructed the international competitiveness index system of cultural industry from value creation and value realization, and compared the international competitiveness of cultural industries between China and other countries [3]. They concluded that Chinese cultural industry is in the low-end of industry chain. Huang selected productive factors, demand conditions, corporate strategies, government factors and related industries as five indicators, using principal component analysis to conduct multivariate statistical analysis of 33 countries including China, the United States, Japan and South Korea, and concluded that The US cultural industry has strong international competitiveness, and Chinese cultural industry still need to be improved [4].

The research methods of the measurement of cultural industry mainly include cluster analysis, analytic hierarchy process, normal normalization method, competitiveness index and principal component analysis [5]. In recent years, scholars in China have frequently used the competitiveness index to measure the competitiveness of cultural industries. Three main indicators introduced as domestic market share index and international market share index to indicate the market share; trade division index and trade competitiveness index to indicate trade balances; export similarity index and revealed comparative advantage index and revised revealed comparative advantage index. Each category can measure the extent of the international competitiveness of the cultural industry from different perspectives.

In addition, $\mathrm{Qu}$ used the import and export data of creative products and creative services in China and the United States separately from 2002 to 2008 in the UNCTAD database to compare the international competitiveness of creative 
industries in both countries, and believed that China should give full play to its elements endowment advantages to promote the international competitiveness of creative industries [6]. Shang and Tao concluded that China's creative industry, with its low-cost labor advantage, showed strong international competitiveness in the international division of labor [7]. Nie revealed the competitiveness and complementarity between China and BRICS by comparing trade structure and scale of the creative industries [8]. Wang and Zhao measured the international competitiveness of China-US film industry from the perspective of global value chain, and believed that China's film industry is still at the low end of the global value chain, and is still in a disadvantaged position in high-end links such as film and television industries [9].

Gao and Yan compared the international competitiveness of creative products and service trade between China and Japan and concluded that the Chinese creative industries tend to develop professionally, while the Japanese creative industries tend to be integrated [10]. In the field of research on the international competitiveness of the publishing industry, domestic scholars have made some progress. Huang and Tian compared China and its nine trade partners from horizontal and vertical angle and believed that Chinese cultural industry is the weaker one [11].

The uniqueness of this paper lies in three points:

Firstly, this paper analyzes the fundamentals of the international publishing market, which describes the basic situation of the publishing market in developed and developing countries, using numerous data to compares and analyzes the development of publishing industry in different countries.

Secondly, this study uses Revealed Comparative Advantage Index (RCA) to represent international competitiveness of China's publishing industry, which is very persuasive.

Thirdly, this study adopts Gray Relational Analysis and critical indicators to weight influencing factors in determining international competitiveness of China's publishing industry, as most of the research only analyzes its influencing factors from a theoretical perspective.

So this paper makes empirical contributions to studies of the competitiveness of China's publishing industry. In the understanding of previous research on the international competitiveness of the publishing industry, we believe that relating study still remain in the deepening stage in China.

The rest of the paper is organized as follows: Section 2 presents fundamentals of the international publishing market. Section 3 presents the influencing factors of international Competitiveness via GRA, which offers empirical methods and data description, algorithm on GRA and results of GRA. Section 4 presents conclusion and suggestions

\section{Fundamentals of the International Publishing Market}

Supply side and demand side of publishing market need be observed according to major fundamentals and their changes. For an instance, digital wave has dri- 
ven the e-book market rapidly, "the cost of reading has dropped while selection has increased dramatically" [12] but evidences show that paper books are still the leading force currently in international publishing market. A survey ${ }^{1}$ reveals that paper books still account for half of total demand while more and more people are reading e-books. In addition, audiobooks are prospering overtime. In the 2016, at least $65 \%$ of Americans read a paper book a year, $28 \%$ of Americans read at least one e-book a year, and $14 \%$ of Americans chose audiobooks. As shown in Figure 1, from 2011 to 2016, the number of paper book readers in the United States has always been above 60\%, underpinning its traditional publishing industry in advantageous position.

In recent years, some developed countries have experienced negative economic growth and saturation of the market leading to negative growth in the publishing markets. Book publishing varieties in the US and S. Korean were 191,576 and 45,213 , down by $4.6 \%$ and $4.9 \%^{2}$ respectively in 2015 . In terms of book sales, book sales in the US, Japan and Germany have seen a decreasing trend. In 2015, US book sales were US $\$ 27.78$ billion, down by $0.6 \%$ year-on-year. In Germany, it was US $\$ 10.68$ billion, down by $1.4 \%$ year-on-year; in Japan, it was US $\$ 13.9$ billion, down by 5.3\% year-on-year. Japan's total sales of books and periodicals for 11 consecutive years showed negative growth. As for periodicals publication, the total revenue of the US in 2015 was $\$ 29.4$ billion, showing a decrease of 3.7\% year-on-year; the circulation and varieties of French newspapers showed a decreasing trend in 2015; Japanese periodicals sales has declined for 18 consecutive years, and created a new low in history in 2015.

In emerging economies we also find a continued growth in international publishing market. In 2015, South Africa's publishers' net income was 29 billion South African Nantes (about 2.1 billion RMB), of which education publications accounted for $64 \%$, trade publications accounted for $27 \%$, and academic publications accounted for $9 \%{ }^{3}$. In the past decade, the openness of the Chinese publishing product market has continued to increase, showing the increasing internationalization of the Chinese publishing industry. In 2015, the import value of books, newspapers, periodicals, audio-visual products, electronic publications and digital publications was $\$ 183.5135$ million, and the export value was $\$ 34.9819^{4}$. By 2015 , its import and export volume rose to $\$ 853.2273$ million and $\$ 104.8557$ million. In Copyright item, China imported a total of 16,467 copyrights and exported 10,471 copyrights. The types of copyright trade also continued to experience a deficit. Book copyright is still the main target of copyright introduction. The overall trade deficit continued to expand in the account of China.

The US and UK are the main countries with the largest number of copyrights exports to China while China's export to Taiwan is the most. Since domestic ${ }^{1}$ The Pew Research Center survey was a telephone survey conducted by Pew Research Center. 1520 Americans are surveyed from March to April in 2016.

${ }^{2}$ Source: “International Publishing Industry Development Report (2016 Edition)".

${ }^{3}$ Source: Publishers' Association of South Africa, Publishing Industry Survey, 2015.

${ }^{4}$ Source: "Basic Situation of the National Press and Publishing Industry in 2015". 


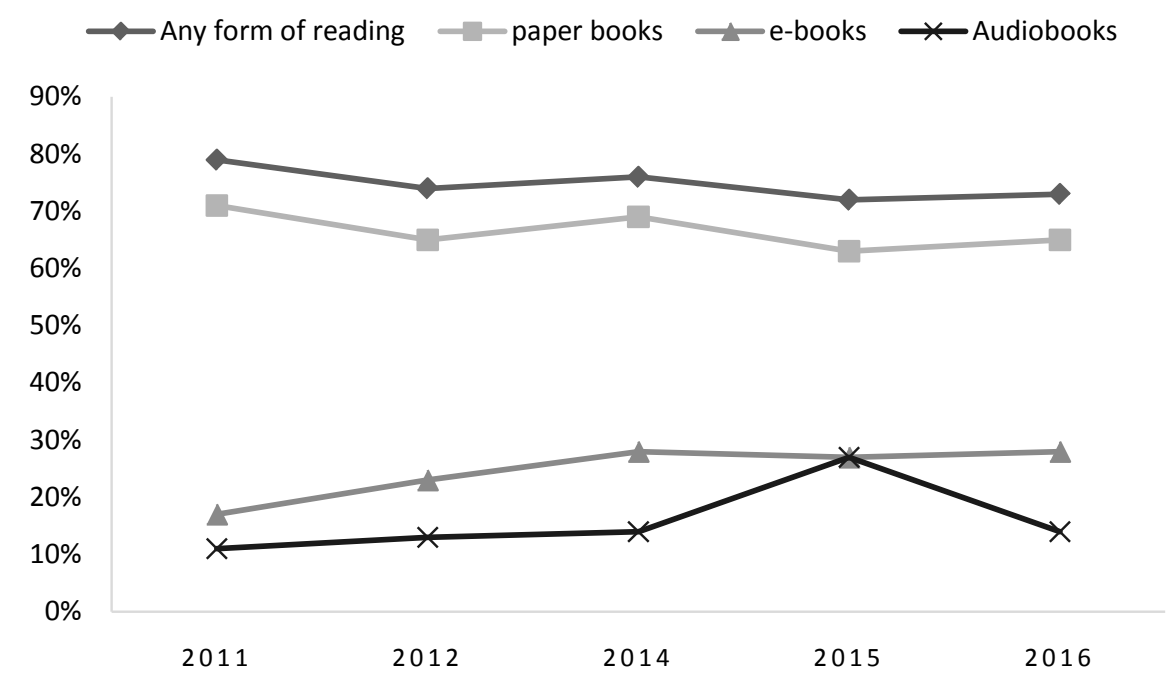

Figure 1. American reading habits. Source: Pew Research Center, Book Reading, 2016.

publishing industry concentration is not high, in addition to few large publishing groups, many small and medium-sized enterprises have a very low international market share, lacking of competitiveness in copyright output. Due to the tariffs and other expenses in the copyright trade, the incentives are relatively very low, reducing enterprises' enthusiasm for the export of copyright. Furthermore, the lack of professional copyright agency companies and professionals is also an important reason for copyright trade deficit.

\section{Influencing Factors of International Competitiveness via GRA}

\subsection{Empirical Methods and Data Description}

In order to measure factors' impacts on the international competitiveness of China's publishing industry, we use Gray Relational Analysis (Deng, 1984). This study selects RCA of Chinese publishing industry during 2007-2015 as reference series, with the number of students, the expenditure of scientific research, the per capita disposable income, the average consumption tendency, the internet penetration rate, education funding, industrial concentration number of projects funded by the National Publishing Fund as comparative series. By calculating the Grey Relational Coefficient and Grey Relational Grade, this paper attempts to weight the influencing factors of international competitiveness of Chinese publishing industry. The main variables are described as follows:

1) Production Factor. Publishing industry is a knowledge-intensive industry, and human capital is the internal driving force to promote the growth of publishing industry. The number of students (tens of thousands) in ordinary colleges represents typical human capital. We also take the expenditure of scientific research as a variable.

2) Demand. This paper uses per capita disposable income and average consumption tendency as the index of demand situation. The average consumption 
tendency refers to the proportion of the per capita disposable income spent by cultural and educational entertainment consumption, which reflects people's demand for cultural industries.

3) Supporting industries. The information industry provides a way of cultural dissemination for the development of the publishing industry by digital media. The Internet penetration rate represents overall development level of the information industry. In addition, we use education funds to measure the level of education investment in a country.

4) Enterprise Strategy, Structure and Competition. This thesis uses industrial concentration as an index to measure the degree of industrial competition. The degree of industrial concentration is the market share of the top eight publishing enterprises in China.

5) Government. Publishing industry relies on the government support to a large extent. The number of projects funded by the National Publishing Fund is the main indicator (the reverse effect of government regulation on the trade of publishing products is not considered).

The source of the data of RCA for the publishing industry is UNCTAD Creative Economy Database, and the data is only updated to 2015. The data of comparison series are derived from the China Statistical Yearbook and the National Publishing Fund. Since some of the data of the relevant variables from the China Statistical Yearbook have only started in 2007, the year of data is from 2007 to 2015. As shown in Table 1, there are 72 observations in the sample data.

\subsection{Algorithm on GRA}

First, we set the reference series and comparative series which report the system characteristics, then make the variable sequence dimensionless. Since we use stable series of social and economic systems and they have trend changes, so we conduct initial value transformation, with 2007 year as the benchmark.

Table 1. Descriptive statistics of variables.

\begin{tabular}{|c|c|c|c|c|c|c|}
\hline Variable & Description & Numbers & Mean & $\begin{array}{l}\text { Standard } \\
\text { Deviation }\end{array}$ & Minimum & Maximum \\
\hline$Y$ & RCA & 9 & 0.622247 & 0.055646 & 0.541240 & 0.711874 \\
\hline$X_{1}$ & Human capital & 9 & 2291.474 & 245.4843 & 1884.9 & 2625.297 \\
\hline$X_{2}$ & $\begin{array}{l}\text { The expenditure of } \\
\text { scientific research }\end{array}$ & 9 & 169.0564 & 73.02707 & 74.7 & 275.0579 \\
\hline$X_{3}$ & $\begin{array}{c}\text { The per capita } \\
\text { disposable income }\end{array}$ & 9 & $21,951.65$ & 5919.571 & $13,785.8$ & $30,843.42$ \\
\hline$X_{4}$ & $\begin{array}{c}\text { The average } \\
\text { consumption tendency }\end{array}$ & 9 & 0.084317 & 0.005404 & 0.0782226 & 0.096418 \\
\hline$X_{5}$ & The internet penetration rate & 9 & 36.24444 & 11.8161 & 16 & 50.3 \\
\hline$X_{6}$ & Education funding & 9 & $2.39 \mathrm{e}+08$ & $8.67 e+07$ & $1.21 \mathrm{e}+08$ & $3.65 e+08$ \\
\hline$X_{7}$ & Industrial concentration & 9 & 0.139758 & 0.006413 & 0.131626 & 0.131626 \\
\hline$X_{8}$ & Government support & 9 & 291.3333 & 128.8235 & 95 & 53 \\
\hline
\end{tabular}


Set reference series as $Y=\{Y(k) \mid k=1,2, \cdots, n\}$

The variable RCA index is a reference series.

The respective variables make up the comparative series:

$$
\begin{gathered}
\left\{X_{1}(k), X_{2}(k), \cdots, X_{i}(k)\right\}=\left\{\begin{array}{c}
X_{11}, X_{12}, \cdots, X_{1 n} \\
X_{21}, X_{22}, \cdots, X_{2 n} \\
X_{m 1}, X_{m 2}, \cdots, X_{m n}
\end{array}\right\} \\
x_{i}(k)=\frac{X_{i}(k)}{X_{i}(l)}, k=1,2, \ldots, n ; i=1,2, \ldots, m
\end{gathered}
$$

$x_{i}(l)$ is the initial value.

Carry out the subtraction operation to the reference series and comparative series and calculate the absolute value.

$$
\begin{aligned}
& \Delta(\min )=\min _{i}\left(\min _{i}\left|X_{0}(k)-X_{i}(k)\right|\right) \\
& \Delta(\max )=\max _{i}\left(\max _{i}\left|X_{0}(k)-X_{i}(k)\right|\right)
\end{aligned}
$$

$\Delta(\min )$ is minimum deviation for the second level, $\Delta(\min )=0.0000$

$\Delta(\max )$ is maximum deviation for the second level, $\Delta(\max )=2.3669$

$$
\xi_{i}(k)=\frac{\min _{i} \min _{k}\left|X_{0}(k)-X_{i}(k)\right|+\rho \max _{i} \max _{k}\left|X_{0}(k)-X_{i}(k)\right|}{\left|X_{0}(k)-X_{i}(k)\right|+\rho \max _{i} \max _{k}\left|X_{0}(k)-X_{i}(k)\right|}
$$

$\xi_{i}(k)$ is the difference value between the reference curve and comparative curve at k time, which is the correlation coefficient of $X_{i}$ to $X_{0}$ at $k$ time.

$\rho \in(0,1)$, generally take it as 0.5 .

$$
r_{i}=\sum_{i=1}^{N} \xi_{i}(k)
$$

$r_{i}$ is gray relational grade of curve $X_{i}$ to reference curve $X_{0}$. This thesis calculate gray relational grade to judge the influence of each influencing factor on the research object.

\subsection{Results of GRA}

As for the grey relational grade, "Chen ever took 0.7 and 0.8 as the boundary to divide the grey relational grade into 3 echelon" [13]: the degree greater than 0.8 ; the degree between $0.7-0.8$; the degree lower than 0.7 . The greater the grey relational degree, the lager the influence of the factors on RCA of publishing industry.

As shown in Table 2, the degree of relevance of the influence factors of the international competitiveness of China's publishing industry is as follows: The number of students in the general college $>$ The degree of industrial concentration $>$ The average consumption tendency $>$ The National Publishing Fund to support $>$ The per capita disposable income $>$ Education funds $>$ Expenditure on scientific research $>$ Internet penetration rate. The ranking order of above factors then occurs. 
Table 2. Order of gray relational grade.

\begin{tabular}{ccccccccc}
\hline Variable & $X_{1}$ & $X_{2}$ & $X_{3}$ & $X_{4}$ & $X_{5}$ & $X_{6}$ & $X_{7}$ & $X_{8}$ \\
\hline Gray relational grade & 0.9482 & 0.5929 & 0.7555 & 0.8198 & 0.5637 & 0.6486 & 0.8689 & 0.7816 \\
Order & 1 & 7 & 5 & 3 & 8 & 6 & 2 & 4 \\
\hline
\end{tabular}

The correlation between the international competitiveness of China's publishing industry and the number of students in college is as high as 0.9520 , which shows that human capital plays a leading role in the international competitiveness of the publishing industry.

As for industrial concentration, it shows that scale economy to a large extent affects the international competitiveness of the publishing industry.

The correlation degree of average consumption tendency is greater than 0.7, which indicates that the characteristics of consumption demand in China affect the overall development level and international competition level of China's publishing industry.

The number of projects funded by the National Publishing Fund indicates the government's support for the publishing industry is also very imperative.

The expenditure of education funds and scientific research has affected the international competitiveness of China's publishing industry to a certain extent, but the degree of influence is general.

The correlation between the international competitiveness of China's publishing industry and internet penetration rate is the smallest, which indicates that the digitalization of China's publishing industry is still not high.

\section{Conclusions and Suggestions}

This study measures the influencing factors of international competitiveness of Chinese publishing industry via Gray Relational Analysis, and the results show that human capital as an advanced production factor plays a leading role in international competitiveness of Chinese publishing industry. Industrial competition obviously affects the scale of China's publishing industry and its competitiveness. The demand for cultural consumption drives the upgrading of China's publishing industry and enhances its international competitiveness. The government's support facilitates the enhancement of the international competitiveness of Chinese publishing industry. The influence of supporting industries like education and information industries on the development of the publishing industry is weak, due to the incomplete industry chain and the low level of corporate engagement.

In accordance with the empirical testing, our policy suggestion mainly goes to critical factor improvement. The details are as follows:

First, it is necessary to train senior publishing talents and give full play to the advantages of human capital. Knowledge-based talents provide intellectual support for the development of the publishing industry. In the international copyright market, the shortage of publishing industry is not only excellent editors, 
but also compound talents who are familiar with publishing knowledge and copyright trade rules. It is important to create a healthy environment conducive to the long-term development of publishing talents and give full play to the benefits of talents.

Second, China needs to reinforce cultural resource endowment to meet the growing demand for readers. The long-standing Chinese cultural resources have provided favorable conditions for the improvement of production capacity. But these cultural resource endowments have not yet been fully explored and reasonably utilized. As a key link of cultural industry, publishing industry plays an important role in satisfying people's spiritual and cultural needs. Cultural resources are renewable, repeatable and exploited resources, so it's imperative to fully rely on cultural resource endowment, form cultural production capacity, enhance the level of Chinese cultural industry, optimize the structure of cultural industry, and promote the development of related industries. The publishing industry should continue to provide users with high-quality reading resources to meet people's growing reading needs.

Thirdly, the industrial chain needs to widen and accelerate the digitalization of the publishing industry. As digital publishing is prevailing, the integration of information industry long locked in low length value end will narrow China's profit margin. The industry chain can extend to business areas such as read-based media implantable advertising, e-commerce, social networking, and intelligent data mining. Taking intelligent data mining as an example, mobile device providers have direct commercial interest relationship with end users, record and analyze a large amount of user data information, and realize the full utilization of information. If the publishing enterprises can accurately grasp the needs of users, the market share of their products will increase substantially, driving the development of the entire industry.

Finally, China can increase the government's support for the publishing industry and loosen regulations in reference to international regulation and practice. The government's macro-control and subsidy to the publishing industry should conform to the rules of market operation so as to better integrate with the international market. To achieve effective competition in the publishing industry, the government should improve the entry and exit mechanisms of the publishing industry.

\section{Fund Sponsored}

Research Fund Sponsored by China National Fund for Social Science Research Project "On the Core theory of Global Layout for China's Strategic Emerging Industry” (17BJL015).

\section{Conflicts of Interest}

The authors declare no conflicts of interest regarding the publication of this paper. 


\section{References}

[1] Zhang, B. and Du, X.Y. (2012) Analysis on International Competitiveness and Influencing Factors of America's Cultural Industries. International Business. Journal of International Business and Economics, No. 4, 81-91.

[2] Tang, X.H. and Li, B. (2012) The International Competiveness of the Japanese Cultural Industry and the Prospects for Development. Contemporary Economy of Japan, No. 4, 47-55.

[3] Lan, Q.W., Zheng, P. and Han, J. (2012) International Competitiveness Comparison and Promotion Strategy of China's Cultural Industry-Based on 2011 Cross-Section Data. Finance \& Trade Economics, No. 8, 80-87.

[4] Huang, Y.J. (2013) Empirical Research on the International Competitiveness of American Cultural Industry. Liaoning University, Shenyang.

[5] Fu, L.P., Song, J.S., Deng, J., et al. (2010) A Summary of the Research on the Competitiveness and Evaluation of Cultural Industry. Academic Forum, 33, 168-171.

[6] Qu, G.M. (2012) Comparison of International Competitiveness of Creative Industry between China and USA: Based on RCA, TC and "Diamond" Model. Journal of International Trade, No. 3, 79-89.

[7] Shang, T. and Tao, Y.F. (2011) On International Division of Labor in China's Creative Industry: An Analysis Based on the Comparison between Developed and Developing Countries. World Economy Study, No. 2, 40-47.

[8] Nie, L. (2013) A Study of the International Competitiveness of the Trade in Creative Products of the BRICs. Journal of International Trade, No. 2, 111-122.

[9] Wang, G.A. and Zhao, X.Q. (2013) A Comparative Study on International Competitiveness of Sino-US Movie and Television Industry: Based on the Perspective of Global Value Chain. Journal of International Trade, No. 1, 58-67.

[10] Gao, H. and Yan, L.T. (2017) A Comparative Analysis of International Competitiveness of Creative Industries between China and Japan: New Measurement Based on the Change of Creative Products and Service Trade. Contemporary Economy of Japan, No. 1, 66-80.

[11] Huang, X.R. and Tian, C.Q. (2014) Research on the International Competitiveness of China’s Publishing Industry. China Publishing Journal, No. 3, 8-12.

[12] Rosenblatt, G. (2015) The Automation of the Publishing Industry.

[13] Chen, B.B. (2015) Grey Relational Analysis of Factors Influencing the International Competitiveness of China's Transport Services Trade. Reform \& Opening, No. 23, $10-12$. 